\title{
Tahrir Defterlerine Göre Rumeli’de Kale Teşkilatına Kırçova Kalesi Örneğinden Bir Bakış (1515-1542)
}

\section{A View From The Case of Kurçova Castle To The Castle Organization In Rumelia According To Tahrirs (1515-1542)}

\section{Galip Çağ a,*}

${ }^{a}$ Dr. Öğr. Üyesi, Bolu Abant İzzet Baysal Üniversitesi, Fen Edebiyat Fakültesi, Tarih Bölümü, 14030, Bolu/Türkiye. ORCID: 0000-0001-8170-6053

\section{MAKALE BİLGİSI}

Makale Geçmişi:

Başvuru tarihi: 31 Ocak 2020

Düzeltme tarihi: 11 Şubat 2020

Kabul tarihi: 27 Şubat 2020

\section{Anahtar Kelimeler:}

Osmanlı

Rumeli

Kırçova/Kicevo

Kale

Tahrir

\section{A R TICLE INFO}

Article history:

Received 31 January 2020

Received in revised form 11 February 2020

Accepted 27 February 2020

\section{Keywords: \\ Ottoman \\ Rumeli \\ Kicevo \\ Casttle \\ Tahrir}

\section{ÖZ}

Osmanlı idaresinin Rumeli politikasında coğrafi unsurlar her zaman mühim rol oynadı. Kadim yollar (via agnatia, via militaris vd.) geçitler, suyolları bu manada hem fetih güzergâhları hem de sonrası için belirleyici ve yönlendirici birer dış etkendi. Osmanlılar da bu değișemeyecek etkenleri yeni organizasyon ve inşa çalışmaları ile birer avantaja dönüştürmeye çalıştılar. Bir başka anlamda da doğal engelleri aştılar.

Rumeli'de bahsi geçen bu yeni organizasyonun en belirgin noktalarından biri de kale inşa ve organizasyonu oldu. Eski kalelerin tadili ve genişletilmesi yanında yeni kalelerin de inşası gerekli bir durumdu. Bu çalışma, 16. yüzyılın ilk yarısında Rumeli'nin en batı ucunda yer alan Kırçova/Kicevo şehri kalesinin durumunu ortaya koymaya çalışacaktır.

\section{Giriş}

Osmanlıların Rumeli'ne çıkıșı ve sonrasında hızlı ilerleyişinin sebepleri farklı vesilelerle incelendi. İstimalet, sosyal devrim ve öncülerin bölgede hazırladığı ortam durumun insana dairleri açısından değerli tespitlerdi. Ama bunun yanında yollar, strateji, coğrafya ve doğal kaynakların geliştirdiği konjonktür de bu ilerleme/yerleşme sürecine doğrudan tesir etti. Kadim yollara uyumlu hareket, coğrafyanın zorunlu kıldığ 1 yeni yerleşme tipleri (derbentler gibi) güvenlik ihtiyacının sonuna dek hissedildiği bol geçitli ve yükseltili ön görülemez sahalar baştan inşa edilmiş bir askeri teşkilatı kaçınılmaz kıldı. Şüphesiz bu yeni düzen ile birlikte sadece yolların değil şehirlerin de güvenliği sorunu göz önüne alındı. Hemen her şehrin içinde inşa edilmiş kaleler -ki bunların önemli bir kısmı Osmanlı öncesi dönemde hali hazırda var olan yapılar idi- bu manada tadil

Sorumlu yazar/Corresponding author.

e-posta: galipcag@gmail.com

e-ISSN: 2149-4622. (C) 2013-2020 Muş Alparslan Üniversitesi. TÜBİTAK ULAKBİM DergiPark ev sahipliğinde. Her hakkı saklıdır. http://dx.doi.org/10.18506/anemon.683071 
edilerek iç teşkilatlanması özel bir statü ile yeniden kurgulandı. Vergi sistemine yerleştirildi ve bir takım özel statüler tesis edildi. Böylece bu kritik unsurların merkez tarafindan takip ve müdahalesi mümkün kılındı.

Osmanlı Devleti Rumeli'ne çıktığında, ortaçağda mutat olduğu üzere birçok şehir hâlihazırda bir kale etrafında teşekkül ediyordu. Ve bu kalelerin önemli kısmı da ayakta ve fiziksel olarak kullanılabilir durumda idi. Çoğu zaman şehrin fethi, Osmanlı birliklerinin gelişinden haberdar olup kale içine sığınan halkın kaleyi teslimi ile aynı manaya geliyordu. Örneğin 16. yüzyılda önemli bir liman şehri olan Varna'nın nüfusunun \%28'si kasaba, kale ve büyük köylerde yaşarken kalan \%72'si köylerde ikamet ediyordu. (İlhan, 2003: 58)

Çalışmaya konu olan Kırçova, Uskana adı verilen antik bir kent üzerine kurulur. Kaynaklardan anlaşılacağı üzere defaatle işgale ve istilaya uğrar; buna bağlı olarak da etnik ve dini dönüşümler yaşar. Örneğin 6 . yüzyıl sonlarından 7 . yüzyıl ortalarına kadar Makedonya topraklarının tamamı Selanik hariç, Slavlar tarafindan iskân edilir. Makedonya'da Slav kolonizasyonu sırasında Makedon şehirleri, Hristiyan kiliseleri, kaleler imha edilir ve bunların çevrelerindeki köle sahiplerinin ekonomileri soyulur ve tahrip edilir. Makedonya topraklarına birçok Slav kabilesi yerleşir. $\mathrm{Bu}$ topraklara yerleşen kabilelerden daha büyük bir kısmının isimleri bilinir. Selanik yakınlarında Sagudatlar kabilesi, Selanik şehrin batısında Dragovitiler, Halkidik Yarımadası'nda Rinhinler, Struma ve Ustrumca Irmağı'nın akışı ve etrafında Strumyalılar, Mesta Irmağı etrafinda Smolyanlar ve bugün var olan Köprülü, Kavadar, Pirlepe, Manastır, Kırçova, Debre, Ohri, Prespa ve etrafındaki alana Berzitler kabilesi yerleşir. (Boşkoviç, Maçevska, 2010: 24)

Osmanlı kaynakları Kırçova'nın 1385'te Lala Şahin Paşa tarafından fethedildiğini kaydeder. Sırp kaynakları ise fethin 1395 'te gerçekleştiğini ifade eder. Kırçova'nın fethinden sonra Osmanlılar burada bulunan kalede bir askeri garnizon kurmuşlar ve bir grup Türk halkını kasabaya yerleştirmişlerdir. 1455 tarihli bir tahrir defterinde Kırçova'da 30 Müslüman hanenin (yani 30 aile) 145 de Hıristiyan hanenin olduğu kaydedilmiştir. 1521'de bu say1 artmış ve kasabada yaşayan 178 ailenin 95'i Müslüman olarak kaydedilmiştir. Kasabada Fatih Sultan Mehmet'in inşa ettirdiği cami başta olmak üzere birçok Osmanlı dönemi eseri halen mevcuttur.

I.Bayezid tahta geçip, Anadolu'ya yönelmeden evvel, muhtemelen yokluğunda Balkanlar'da gerçekleşecek bir Haçlı birliğini kırmak hem de takviye kuvvet sağlama amacı ile Sırp kralının oğlu Stefan Lazareviç ile bir anlaşma yaparak kız kardeşi Oliviera (Maria Despina) ile evlenmek ve yardım sağlama sözü alır. (İnalcık, 1992:232) Bundan sonra Stefan özellikle başındaki Macar baskısı nedeni ile Osmanlı Devleti'ne sadık kalır. Ancak parçalanmış bir yönetim arz eden Sırb krallığının yukarı kısmına hükmeden Vuk Brankoviç özellikle bölgesindeki maden şehirlerine sahip olmaya çalışan Osmanlı devletine karşı koyar. Bu sırada devreye giren Paşa Yiğit Bey 1391'de Üsküp'ü ve Kratova gümüş madenlerini alarak daha sonra Bosna ve Arnavutluk'a gerçekleşecek seferler için bir üs elde etmiş olur ki bu bölge Kırçova’ya da oldukça yakın bir noktadır. Kaldı ki buranın fethinden kısa bir süre sonra da Kırçova fethedilir ve Rumeli Eyaleti'nin kurulmasından sonra da fetihlerin yönü sağ kol kazaların alınması ile devam eder ve bu dönemde Kırçova Kazası'da sağ kol kazalar içerisinde yer almaktadır. (370 numaralı Muhâsebe-i Vilâyet-i Rûm- İli Defteri [937/1530], 2001: 5).

\section{Rumeli'de Kale Görevlilerine Karşılaştırmalı Bir Bakış Denemesi}

Bu çalışmada kullanılan iki kaynaktan biri olan 73 numaralı tahrir defteri Paşa livasinın nahiyelerinde bulunan Dimetoka, Üsküb, Kırçova, Pirlepe kaleleri mustahfizlarına aid tımarları ve evkafi mübeyyin icmal defter açıklaması ile kaydedilir. Bir tımar evkaf defteri olarak 1515-1519 tarihleri arasına dair bilgiler verir. Öte yandan diğer kaynak 217 numaralı defter ise Paşa sancağına tabi Üsküb, Kalkandelen, Kırçova, Manastır, Pirlepe, Köprülü nahiyelerinde bulunan ve Üsküb, Kırçova, Pirlepe kaleleri mustahfizlarına aid tımarların icmal defteri olarak kaydedilir. Diğerine karşın bu defter bir tımar defteridir. Bu iki defter kalenin nüfusu, idarecileri ve unvanlarına dair önemli bilgiler verirken iktisadi düzendeki yerlerine dair de bilgiler sunar.

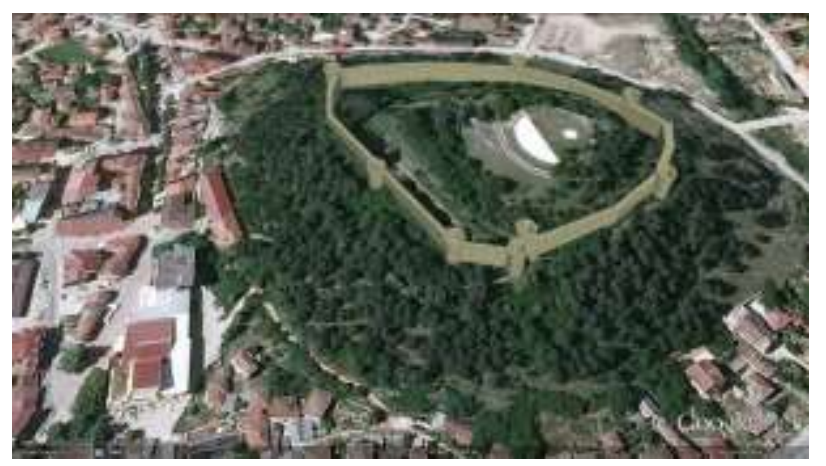

Kırçova Kalesi’nin Güncel Durumu (Cultural Heritage Management Plan For The Project "Revitalization Of Kitıno Kale", 2018: 12.)

Osmanlı kalelerinin en yetkili görevlileri dizdar olarak bilinir. Dizdar "kale, hisar" anlamına gelen Farsça diz kelimesinden türetilir. Kale muhafizlarının kumandanı durumundadır. Türk - İslam şehirlerinde kalenin sadece bir askeri mevki olmaktan çıkması ile askeri görevinin yanı sıra şehrin asayişi, kalede saklanan değerli eşyaların korunması, hapishaneden sorumlu olma gibi çok çeşitli vazifeler de yapmış ve şehrin sosyal hayatı ile yakından ilgili bir görevli olarak önem kazanır. (Oğuzoğlu, 1992: 480-481) Dizdarlar görevleri gereği beylerbeyi, sancakbeyi ve kadıya karşı sorumlu ve onların denetimi altındadır. Herhangi bir başarısızlığı ya da görevini kötüye kullanması halinde bu yöneticilerin arzı ile azledilebilirlerdi. (Ergenç,1995: 79) Dizdarın görevleri arasında kalelerin onarım ve bakımı ile kalede yaşayanların hukuksal sorunlarını çözme işi de yer alırdı. Bu nedenle kendisine doğrudan hüküm gönderilirdi. Örneğin 17. Yüzyıl ortalarında bahse konu hukuki bir soruna dair Varna'ya gönderilen hüküm dikkat çekicidir. (83 Numaralı Mühimme Defteri, 2001: [Hüküm 965] 65) Zira bu hükümden anlaşılacağı üzere dizdarlar cizye tahsili noktasında da önemli bir göreve sahiptir. 
Sâbıkâ İstanbul Kâdîsı olup ber-vech-i arpalık Varna kazâsına mutasarrıf olan ( ) zîdet fazâ'ilüĥ̂ya hüküm ki:

Nefs-i Varna'da olan zimmî re 'âyâ arz-ı hâl sunup; " "Cizyeleri defterde dört yüz seksen hâne iken cem 'na me'mûr olanlar garazan ziyâde hâne tahmîl ve deftere kayditmekle yedi yüz yetmiş hâne olup ve Kazak eşkiyâsı dahı bir kaç seneden berü kasaba-i mezbûreyi yağmâ vü gâret ve nicelerin katl ü hasâret itmekle ancak dört yüz nefer mevcûd olup anlar dahı ziyâde fakîr olmağla ol mikdâr hâne edâsına iktidârları yokdur." diyü a 'lemü'l-ulemâ['i]'l-mütebahhırîn, efdalül-fudalâ'i'lmüteverri în Şeyhu'l-İslâm ve Müfti'l-enâm olan Mevlânâ Yahyâ

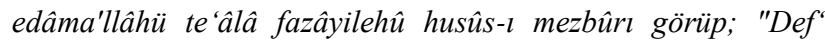
olması mühimmâtdandur." diyü i lâm itmeğin, yüz hânesi fürûnihâde olunup ve yetmiş hânesi tahammüli olan karyelere tahmîl olunmak fermân olunmağla; "Bin otuz beş senesiyçün cizyeleri yedi yüz yetmiş hâneden edâ olunup bin otuz altı senesiyçün elli hâneleri ile altı yüz hâneden oluna." diyü Hazîne-i Amire'de mahfûz olan cizye defterlerine kaydolunup ellerine tuğrâlu vü mühürlü sûret-i defter virilmekle; "Mûcebince amel olunup fürûnihâde olan yüz hânelerinden bir akça ve bir habbe aldurmayasın." diyü Mâliyye tarafindan mü'ekked hükm-i şerîf virilmişken, cizye cemı 'na varanlar ve Tuna defterdârı olanlar girü taleb ü rencîde iderler imiş. Mezbûrlarun hâliyâ Varna Kal'ası ta'mîrinde ziyâde sa 'y ü emekleri vücûda gelüp kal' $a-i$ mezbûreye meremmet lâzim geldükce üzerlerine lâzim gelen hıdmeti eyledüklerinden gayri kal 'a-i mezbûre meremmâtı [içün] her sene kendü aralarında on iki bin akça cem 'idüp ma 'rifet-i şer'le kal'a-i mezbûre dizdârnna teslîm itmeği ta'ahhüd eyledükleri ecilden fürû-nihâde olan hâneleri içün rencîde olunmayup Mâliyye tarafindan virilen emr-i şerîf mûcebince amel olunmak" bâbında emr-i şerîfüm taleb itmeğin, mûcebince amel olunmak emridüp buyurdum ki:

Vusûl buldukda, mezbûrlar mâdâm ki kal'a-i mezbûrenün meremmâtı vâkı' oldukca üzerlerine lâzim gelen hıdmeti edâ idüp kal 'a-i mezbûre meremmâtı içün ta'ahhüd eyledükleri on iki bin akçayı kendü aralarında cem 've ma 'rifet-i şer 'le dizdâra teslìm eyleyüp ellerine temessük alalar, fürû-nihâde olan hâneleri içün ellerinde olan Mâliyye emri mûcebince amel idüp hılâfina cevâz göstermeyesin; şöyle bilesin.

Dizdarlar gece ve gündüz kaleden ayrılmamakla yükümlüydüler. Kale duvarlarından 100 adım uzaklaşması idamını gerektiren bir hareket bile sayılabilirdi. Her dizdar, görevli olduğu kalede mustahfız denen savunma askerlerinin komutanı, kale içinde yaşayan sivil halkın da mülki ve askeri amiriydi. Dizdarların sorumlulukları, kalenin iç kesimde ya da sınır boyunda olmasına göre değişirdi. Sınır boylarındaki kalelerin dizdarları savunma komutanı konumunda iken, iç bölgedeki kalelerin dizdarları güvenlikten sorumluydu. Yedikule, Rumeli

Hisarı ile Amasra ve Sinop kaleleri bir tür hapishane olduğundan buralardaki dizdarlara bu yönden de sorumluluk düşerdi.

Dizdarlar çoğu kez, merkezdeki kapıkulu ocaklarına bağlı orta yayabaşıları arasından atanırdı. Savaş sırasında stratejik konumlu kalelerde "muhafiz paşa" sanıyla komutanlar görevlendirilirdi. $\mathrm{Bu}$ durumda dizdar, muhafız paşanın yardımcısı sayılırdı. Kalelerde dizdara yardımcı kale ağası, yerlikulu, gönüllü, beşli, azap, atlı ulufeci denen askerler bulunurdu. Dizdara ve kale askerlerine, serbest tımar türünden dirlikler verilir, bazen de aylık bağlanırdı.

Kale görevlileri genel itibari ile kale içerisinde kalmaya mecbur idiler. Dizdar kalede mevcut olan askerlerin başı hükmündeydi ve geçerli mazereti olmadan kaleden yüz adımdan fazla uzaklaşması kesinlikle yasaktı. 1542'de (Tapu Tahrir Defteri (TT.d.) 217) dizdar olarak kaydedilmiş üç kişi bulunmaktadır: Üsküp kalesi dizdarı Çavuş (6.000 akçe) Kırçova kalesi dizdarı Yusuf (4.150 akçe) ve Pirlepe kalesi dizdarı Ali. (5.850 akçe) (TT.d. 217, 25, 69, 133) 1515 tarihli 73 numaralı defterde ise Kırçova kale dizdarı Musa Çelebi olarak kaydedilmiştir.

Kale dizdarlarının yardımcıları hükmünde olan kethüdalarda yine bu kategoriye giren önemli görevlilerdir. Zira kale kethüdası da "mâl-ı mîrîye ve kal'aya hizmet eylemekde" dizdarın yardımcısıdır. Kale erlerinin dirlik ve düzeninin sağlanması, diğer hizmetlerin görülmesinde dizdar ile birlikte sorumludur. Tayininde izlenen yol ve bağlı bulunduğu makamlar dizdarınki ile aynıydı. (Batmaz, 1996: 5) Üsküp kalesi beyinin kethüdast Ahmet (1.200 akçe) Kırçova kalesi beyinin kethüdası Derviş Ahmed (1.346 akçe) ve Pirlepe Kalesi beyinin kethüdast Ali (1.400 akçe) 217 numaralı defterde kaydedilmiş olan kale kethüdalarına örnek teşkil eder bu dönemde. (TTT.d. 217: 25, 69, 133 v.)

Dizdar ve kethüda haricinde kalan ve sıradan askerlerden farklı olarak görev ve yükümlülükleri olan diğer bir askeri sinıf da bevvablardı. Bevvab kelime manası olarak kapıcı demek olup aslen saray kapıcılarına verilen bir unvan iken zamanla taşrada da bu işle iştigal eden zümreyi ifade eden bir terim olarak kullanılmaya başladı. Diğer askeri zümrelerin çoğunda olduğu gibi bunların da komutanları mesabesinde birer kapıcıbaşı ve kethüdaları vardı. 16091611 yıllarına ait mevâcib defterlerinden 5 kapıcı neferinin Van Kalesi'nde görev yaptığı kaydedilir. 1755-1756 yıllarında Faş Kalesi ve limanında süvari ve piyade olarak yazılan 198 nefer bevvâb görev yapıyordu örneğin. (Kılıç, 2012: 106)

Bu görevlilerin dişında kalan ve kaleyi korumakla görevli muhafiz sınıfı da kale merdi olarak adlandırılırdı. 217 defter kaydına göre Üsküp kalesinde 14 (toplam 17.073 akçe) Kırçova kalesinde 5 ( toplam 11.206 akçe) ve Pirlepe kalesinde 7 (toplam 5.855 akçe) kale merdi bulunmakta idi. 73 numaralı deftere göre ise Kırçova'daki kale merdi sayısı 16 idi 1515 'te.

Manevi (dini) yaşama ilişkin görevlilere tevcih edilen tımarlara gösterilebilecek en müşahhas örnek hatiplerdir. Hatib, Cuma günleri görevli olduğu camide vaaz veren kişidir. Bu manada etkin bir hitabete sahip olması ve sözü geçer bir kişi olarak bilinmesi onu toplum tabakaları içerisinde, en azından taşrada önemli bir dereceye çıkartmaktadır. 217 numaralı defterde, Kırçova'da ve Üsküp'te olmak üzere iki cami ve buraların hatibi belirtilmiştir. Bunlar Hatib-i Cami-i Bayezid Han (1.500 akçe) ve Hatib-i Cami-i Giyasettin (2.108 akçe)'dir (TT.d. 217, 68, 24)

Manevi hayatta önemli bir rol oynayan diğer bir görevli de kale imamlarıdır. Kale imamları kale dizdarı ile birlikte özellikle kale içerisindeki güvenliği, asayişi ve huzuru sağlamada önemli bir otoritedir. Özellikle yeniçerilere hizmet vermesi noktasında ayrıcalıklıdır. (Kılıç, 2012:101) 1542'de Üsküp kalesi imamı (1.575 akçe), Kırçova kalesi imamı (1.426 akçe) ve Pirlepe kalesi imamı (1.400 akçe) olmak üzere üç kale imamı kaydedilir. (TT.d. 217: 25, 69, 135) İhtimal kalede tek bir imamın bulunması önemini arttıran diğer bir husustur ki tahrir kayıtların her mahallenin 
bir ya da birden fazla imamının bulunması kale imamını diğerlerinden ayırır.

Yukarıda ifade edilen düzen diğer Osmanlı bölgelerindeki kaleler için de geçerli idi elbette. Bölgesel hususiyetlerin yarattığı ve gerektirdiği değişiklikler yok sayılırsa da düzen hemen hemen bu şekilde kurulu idi. Misal 10 Şevval 1101 (17 Temmuz 1690) tarihli bir kayda göre Konya Kalesi'nde dizdardan başka kethüda, imam, müezzin ve 117 kale eri görev yapıyor, dizdarın 10.000, kethüdanın 4000, imamın 2000, müezzinin 1500 akçelik tımarı bulunuyordu. Kale erlerinin tımarları ise 500-1800 akçe arasında değişmekteydi. Yıllık tınar hasılatı, görev yerini uzun süre terk edemeyecekleri için her yıl merkezden gönderilen mübaşir tarafından toplanıyordu. (Oğuzoğlu, 1992: 480-481) $\mathrm{Bu}$ meyanda bir fikir vermesi adına Kırçova kalesinin idari kadrosunu (TT.d. 73, tarih 1515) şu ilde vermek mümkündür:

\begin{tabular}{|c|}
\hline Mustafa beraderi Musa çelebi Dizdar-ı kal'a-i Kırçova \\
\hline $\begin{array}{l}\text { Mevlana Cami el-hatib çelebi Dizdar-ı kal'a-i Kırçova ve } \\
\text { müezzin }\end{array}$ \\
\hline Mahmud b. Yusuf an ferdan-ı Kal'a-i mezbur \\
\hline Mustafa beraderi Musa çelebi Dizdar-ı kal'a-i Kırçova \\
\hline ---- b. Mahmud \\
\hline Yusuf Veled-i Ali \\
\hline İskender \\
\hline Yusuf b. Burak merd-i kal'a-i Kırçova \\
\hline Hüseyin veled-i Sofi kal'a-i Kırçova \\
\hline Süleyman Veled-i Ali kal'a-i Kırçova \\
\hline Yusuf Veled-i Ali kal'a-i Kırçova \\
\hline Pirnazar Veled-i Yusuf \\
\hline Korkud Veled-i Dizdar kal'a-i Kırçova \\
\hline Sofi Ali Kethüda-i kal'a-i Kırçova \\
\hline Muhiddin imam-1 kal'a-i Kırçova \\
\hline ..... kal'a-i Kırçova \\
\hline Mehmed b. ...... kal'a-i Kırçova \\
\hline Ali merd kal'a-i Kırçova \\
\hline Umur merd kal'a-i Kırçova \\
\hline
\end{tabular}

\section{Sonuç}

Osmanlı Devleti'nin kuruluş teorileri ile başlayan Rumeli'ndeki kalıcı düzenin kökleri problematiği bugüne dek birçok saiki ile araştırıldı. Bu araştırmalar sonucunda varılan sonuçlar bütün olarak bakıldığında, devletin Rumeli gibi fiziki ve sosyal olarak karmaşık bir coğrafyada yerleşme sürecinin ciddi bir organizasyon ile gerçekleştiği neticesini verdi. Buna göre Osmanlı idaresinin coğrafi, sosyal, etnik, iktisadi ve inanca dair farklılıklara verdiği tepkinin, bunları merkezi bir sistem içerisinde eritme gailesine bağlı olduğu açıkça ortaya çıktı.

Osmanlı merkeziyetçiliğinin bu manada bütün olarak idari merkezlerin de ötesinde yerel özelliklere göre biçimlenen her türlü idari unsura dair olduğu da açıktır. Bu çalışmaya konu edilen kale düzeninin işleyişi bu çıkarımı doğrulayabilir. Kırçova'da mevcut şehir ve kırsal nüfusun -ki Kırçova çalışmaya konu dönemlerde bölgenin en yoğun kırsal nüfusuna sahiptir- dışında kalenin adeta kendi içerisinde bir şehir sistemi gibi işlemesi her açıdan incelenmeye muhtaç bir durumdur. Kaldı ki sivil nüfusun askeri, dini ve hukuki kaynaklarla idaresi yönetilen-yöneten ilişkisi bağlamında feodal düzenden beridir alış1lagelen bir de facto durumu ifade ederken tamamen askeri bir nitelikte birlikte yaşayan topluluğun buna benzer bir düzenle idaresi kolay olmasa gerektir.

Tahrir defterlerinin (217 ve 73 numaral1) sunduğu verilerden yola çıkarak, kale dizdarı, kethüdası, merdleri, imamı, müezzini, hatibi ve dahi bevvabı merkezli olarak kurulan düzenin diğer tüm kalelerde de var olduğuna dair elimizdeki veriler bu tip çalışmaların varlığının artmasının gerekliliğini ortaya çıkarır. Osmanlı Rumelisinde güvenlik ve savunma kavramlarının bir karşılığı olarak tamamen bu coğrafyaya özel gelişen voynukluk, derbent ve derbentçilik, akıncı teşkilatı ve şehirlerdeki ikametleri meseleleri bu manada sadece askeri değil sosyal olarak da Osmanlı idari düzenini anlayabilmek adına gerekli olacaktır.

$\mathrm{Bu}$ çalışma tarafımızdan yürütülen, öncelikle Makedonya bölgesindeki kalelerin tahrir defterlerine yansıyan verileri doğrultusunda Rumeli'de Osmanlı şehir medeniyetini çözümleme denemesinin ilk evresidir ve girişidir. $\mathrm{Bu}$ manada ilerleyen safhalarda bölgedeki diğer kale düzenlerinin de ortaya konması ile sağlanacak bütüncül bakış tahrirler ışığında yeni bir bakış açısı ve çalışma alanını da ortaya koyacaktır.

\section{Kaynakça}

Cumhurbaşkanlığı Arşivi, Tapu Tahrir Defteri 217 [1542 Tarihli]

Cumhurbaşkanlığ 1 Arşivi, Tapu Tahrir Defteri 73 [1515 Tarihli]

370 numaralı Muhâsebe-i Vilâyet-i Rûm- İi Defteri (937/1530) I.(2001) Başbakanlık Devlet Arşivleri Genel Müdürlüğ̈̈, Osmanlı Arşivi Daire Başkanlığı Yayın Nu: 55, Ankara.

83 Numarall Mühimme Defteri(1036/1037-16261628).(2001)). Devlet Arşivleri Genel Müd. Yay., Ankara.

Batmaz, Eftal Ş. (1996). “Osmanlı Devleti'nde Kale Teşkilatına Genel Bir Bakış”, OTAM, VII, Ankara, 39.

Boşkoviç, Miroslav, Maçevska, D. (2010). Makedonya Tarihi, [Историја на Македонија за 11 година средно стручно образование], Makedonya Cumhuriyeti Milli Eğitim Bak., Üsküp.

Cultural Heritage Management Plan For The Project "Revitalization Of Kitino Kale". (2018), Municiplaity Of Kicevo, Kicevo.

Ergenç, Özer. (1995). Osmanlı Klasik Dönemi Kent Tarihçiliğine Katkı, XVI. Yüzyılda Ankara ve Konya, Ankara. 
643 Çă̆, G./ Anemon Muş Alparslan Üniversitesi Sosyal Bilimler Dergisi, 2020 8(2) 639-643

İlhan, M. (2003). Varna at the end of the Sixteenth Century: Timar Holdings and Population", Romano- Turcica I, ISIS, İstanbul, 51-74.

İnalcık, H. (1992). Bayezid I maddesi, DİA, V, İstanbul, 231234.
Kılıç, O. (2012). Teşkilat ve İşleyiş Bakımından Doğu Hududundaki Osmanlı Kaleleri ve Mevâcib Defterleri, OTAM, 31, Ankara, 87-127.

Oğuzoğlu, Yusuf(1992), Dizdar maddesi, DİA, IX, İstanbul, 480-481. 